\title{
A INTERNET E O LETRAMENTO: RELAÇÕES CONTEXTUAIS NA SOCIEDADE DA CIBERCULTURA - PÓS-MODERNIDADE FRAGMENTADA, DISCURSOS MÓVEIS E CAMBALEANTES
}

\section{THE INTERNET AND LETTERING: CONTEXTUAL RELATIONS IN THE CYBER CULTURE SOCIETY - FRAGMENTED POST MODERNITY, MOBILE AND CAMBALEANT DISCOURSES}

\section{INTERNET Y LA LITERATURA: RELACIONES CONTEXTUALES EN LA SOCIEDAD DE LA CIBERCULTURA - FRAGMENTOS POST-MODERNIDAD, DISCURSOS MÓVILES Y CAMBALEANTES}

\section{RESUMO}

Em um contexto de expansão progressiva das formas de circulação do conhecimento, a internet e as possibilidades de interação e letramento digital que ela propicia, configura um campo de manifestação de práticas situadas a serviço da novas formas de sociabilidades humanas, mediadas pelas Tecnologias Digitais da Informação e Comunicação (TDIC), dando o tom e a caracterização do contexto da cibercultura. Partindo disso, o presente estudo objetiva refletir sobre as influências da internet no processo de letramento do aluno, considerando-se o fenômeno da cibercultura e a influência das TDIC na organização do currículo escolar e aprendizagem do aluno. Metodologicamente, parte de uma pesquisa bibliográfica e exploratória, de abordagem qualitativa, tendo nas leituras de Almeida (2016), Barton; Hamilton (1998), Bauman (2001; 2005; 2016), Castells (1999; 2003), Kenski (2001; 2012), Levy (1994), Lima (2019), Marcuschi (2010), Rojo; Barbosa (2015), Soares (2002), Street (1995; 2014), Xavier (2002; 2005), entre outros, um apoio para construir enlaces entre os principais pontos tratados. Resulta dessa leitura, uma compreensão de que a aproximação entre as possibilidades de interação facultadas pelo mundo da internet e o letramento digital, constitui uma das características fundamentais do atual contexto, marcado pela fragmentação do saber e a necessidade de apropriação crítica e transformadora dos produtos lidos, de modo a construir uma sustentação sólida e eficaz frente aos discursos móveis e cambaleantes que configuram a cena sociocultural, em uma sociedade híbrida, pós-moderna e marcada pelas cargas de valor e sentido à construção do saber cultural do contexto da cibercultura.

Submetido em: 16/01/2020 - Aceito em: 08/04/2020 - Publicado em: 29/04/2020

${ }^{1}$ E-mail: fcorenatolima@ hotmail.com / ORCID: http://orcid.org/0000-0002-1372-5444 / Mestre em Letras - Estudos da Linguagem (UFPI). Professor substituto da Universidade Estadual do Maranhão (UEMA) e professor formador no Centro de Educação Aberta e a Distância (CEAD) da Universidade Federal do Piauí (UFPI), Brasil. 


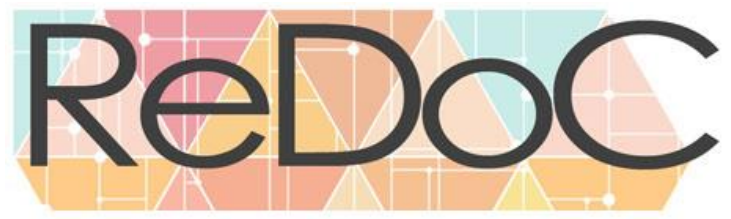

Revista Docência e Cibercultura

PALAVRAS-CHAVE: Internet. Letramento digital. NTIC. Cibercultura. Prática pedagógica.

\begin{abstract}
In a context of progressive expansion of the forms of knowledge circulation, the internet and the possibilities of interaction and digital literacy that it provides, configures a field of manifestation of practices situated at the service of new forms of human sociability, mediated by Digital Information Technologies. and Communication (TDIC), setting the tone and characterization of the cyberculture context. From this, the present study aims to reflect on the influences of the internet on the student's literacy process, considering the cyberculture phenomenon and the influences of ICDT on the organization of the school curriculum and student learning. Methodologically, part of a bibliographic and exploratory research, with qualitative approach, taking the readings of Almeida (2016), Barton; Hamilton (1998), Bauman (2001; 2005; 2016), Castells (1999; 2003), Kenski (2001; 2012), Levy (1994), Lima (2019), Marcuschi (2010), Rojo; Barbosa (2015), Soares (2002), Street (1995; 2014), Xavier (2002; 2005), among others, support to build links between the main points addressed. This reading results in an understanding that the approximation between the possibilities of interaction provided by the internet world and digital literacy constitutes one of the fundamental characteristics of the current context, marked by the fragmentation of knowledge and the need for critical and transformative appropriation of the products read., in order to build a solid and effective support against the moving and reeling discourses that shape the sociocultural scene, in a hybrid society, postmodern and marked by loads of value and meaning to the construction of cultural knowledge from the context of cyberculture.
\end{abstract}

KEYWORDS: Internet. Digital literacy. NTIC. Cyberculture. Pedagogical practice.

\title{
RESUMEN
}

En un contexto de expansión progresiva de las formas de circulación del conocimiento, internet y las posibilidades de interacción y alfabetización digital que proporciona, configura un campo de manifestación de prácticas situadas al servicio de nuevas formas de sociabilidad humana, mediadas por las Tecnologías de la Información Digital. y Comunicación (TDIC), estableciendo el tono y la caracterización del contexto de la cibercultura. A partir de esto, el presente estudio tiene como objetivo reflexionar sobre las influencias de internet en el proceso de alfabetización de los estudiantes, considerando el fenómeno de la cibercultura y los influencias de ICDT en la organización del currículo escolar y el aprendizaje de los estudiantes. Metodológicamente, parte de una investigación bibliográfica y exploratoria, con enfoque cualitativo, tomando las lecturas de Almeida (2016), Barton; Hamilton (1998), Bauman (2001; 2005; 2016), Castells (1999; 2003), Kenski (2001; 2012), Levy (1994), Lima (2019), Marcuschi (2010), Rojo; Barbosa (2015), Soares (2002), Street (1995; 2014), Xavier (2002; 2005), entre otros, apoyan la construcción de vínculos entre los principales puntos abordados. Esta lectura resulta en la comprensión de que la aproximación entre las posibilidades de interacción proporcionadas por el mundo de internet y la alfabetización digital constituye una de las características fundamentales del contexto actual, marcada por la fragmentación del conocimiento y la necesidad de apropiación crítica y transformadora de los productos leídos., para construir un apoyo sólido y efectivo contra los discursos conmovedores y tambaleantes que dan forma a la escena sociocultural, en una sociedad híbrida, posmoderna y marcada por cargas de valor y significado para la construcción del conocimiento cultural desde el contexto de la cibercultura.

PALABRAS CLAVE: Internet. Alfabetización digital. NTIC. Cibercultura. Práctica pedagógica. 


\title{
CONSIDERAÇÕES INICIAIS
}

\begin{abstract}
Pós-modernidade, modernidade líquida, hipermodernidade, modernidade tardia: são várias as expressões que procuram definir o atual momento político, econômico, social e cultural. Diversas análises evidenciam que a sociedade transformou-se significativamente nas últimas cinco décadas. Entre outros aspectos, as inovações tecnológicas tornaram-se preponderantes na vida cotidiana. Celulares, computadores, softwares e redes virtuais de comunicação influem diretamente na hibridização de hábitos, costumes, formas de se relacionar, levando-nos a questionar os pilares que sustentam a sociedade ocidental.
\end{abstract}

(NEIRA; LIPPI, 2012, p. 608)

Motivado pelo pensamento dos autores da epígrafe acima, inicio esta reflexão pensando na força centrífuga que tem movido o mundo das tecnologias e, em especial, o incontrolável avanço das mídias virtuais e das redes de comunicação móvel, que paralelo a expansão das formas de comunicação no mundo, têm representado um desafio para a educação do século XXI. Isso no que se refere a manutenção de sua tradição na relação ensino e aprendizagem e o ensino das múltiplas linguagens ou multilinguagens (SILVA; LIMA, 2018), com o intuito de acompanhar a magnitude das revoluções tecnológicas nas práticas escolares e nos sistemas de uso crítico e reflexivo das virtualidades do mundo do internet.

Vive-se um tempo em que a "mescla de configurações dão o tom a uma pós-modernidade fragmentada, marcada por discursos móveis e cambaleantes" (LIMA, 2019, p. 47) (Grifos do autor). Esse cenário impõe a necessidade de redefinição, revisão e substituição dos modelos convencionais de organização das práticas de ensino. Uma proposta de ensino que traga à baila o reconhecimento e a valorização dessa verdadeira mudança global, deve começar pela descristalização dos moldes estruturalistas do ensino e adoção de uma concepção sociointeracionista e dialogal em suas práticas.

Tudo isso, em virtude de que a influência das diversas formas de transformações culturais tem refletido diretamente nas formas como a educação se processa e define seus propósitos de ocupação social na sociedade da cibercultura. Assim, tem sido o avanço nas Tecnologias Digitais de Informação e Comunicação (TDIC), das mídias tecnológicas e das redes da web que, com acelerados processos de crescimento entre as massas sociais, têm conseguido alcançar propósitos de aproximação, reconhecimento e valorização de múltiplas formas de expressões culturais e de manifestação da linguagem.

Esses novos formatos de práticas comunicativas refletem os caminhos de uma sociedade hipermoderna, marcada por multissemioses, multiletramentos e hiperletramentos (ROJO; BARBOSA, 2015), que se imbricam no tecido social e educacional, a partir das mídias e das tecnologias digitais, as quais compõem a paisagem das práticas interativas no mundo da cibercultura e do letramento digital. No seio dessa configuração, flutuam formas similares de 
referir-se a essa sociedade, como pós-modernidade (GARLAND, 2008; HALL, 2011), modernidade líquida (BAUMAN, 2001; 2005), modernidade tardia (GIDDENS, 2002; HALL, 2011; YOUNG, 2007), modernidades múltiplas (EISENSTADT, 2001), modernidades alternativas (FERRERAS; BRUCE, 2009) e variedades de modernidade (SCHMIDT, 2007), na esfera dos estudos culturais e sociológicos.

Conta-se, neste cenário, com a presença, quase que determinante, da internet, como rede de informações que conecta e cria possibilidade de integração e interação entre culturas, sociedades e sujeitos, transformando significativamente os modos como se processam as formas inferenciais de circulação de informações e construção de conhecimento na sociedade, possibilitando assim, a valorização de letramentos múltiplos que surgem neste cenário.

Na dimensão do espaço da sala de aula, isso significa que:

Novas maneiras de pensar e de conviver estão sendo elaboradas no mundo das comunicações e informática. As relações entre os homens, o trabalho, a própria inteligência dependem, na verdade, da metamorfose incessante de dispositivos informacionais de todos os tipos. Escrita, leitura, visão, audição, criação e aprendizagem são capturados por uma informática cada vez mais avançada. (LEVY, 1994, p. 07)

Na escola, a influência dessa cultura tecnológica e midiática, veiculada pela internet é visível na postura dos alunos, na forma como interagem, comunicam-se uns com os outros e tornamse sujeitos da comunicação, ou seja, apropriam-se de formas de falar, vestir-se, comportar-se e expressar seu lugar no mundo, a partir da influência advindas das relações vivenciadas na internet, principalmente nas redes sociais, $b \log s$, entre outros espaços, onde afloram os múltiplos letramentos da relação sujeito e escrita virtual.

Com o propósito de discutir acerca das relações entre língua e comunicação digital nos adventos da contemporaneidade, chamada de cibercultura e, principalmente, como isso tem sido recebido e tratado pela escola, busca-se, neste estudo, refletir sobre as influências da internet no processo de letramento do aluno, considerando o fenômeno da cibercultura e as influências das TDIC na organização do currículo escolar e da aprendizagem do aluno.

A constituição metodológica parte de uma pesquisa bibliográfica e exploratória, de abordagem qualitativa, apoiada nas leituras de Almeida (2016), Barton; Hamilton (1998), Bauman (2001; 2005; 2016), Behrens (2005), Castells (1999; 2003), Kenski (2001; 2012), Levy (1994), Lima (2019), Marcuschi (2010), Rojo (2009), Rojo; Barbosa (2015), Soares (2002), Street (1995; 2014), Xavier (2002; 2005), ao proporem caminhos teóricos que possibilitem uma reflexão articulada entre educação, linguagem, letramento e ensino no contexto da cibercultura.

Além destas considerações iniciais, a tessitura dessas ideias é feita a partir do seguinte 
diálogo: primeiro, trata-se sobre práticas de linguagem e processos de ensino e aprendizagem na sociedade da informação e da comunicação; depois, refere-se ao fenômeno da cibercultura e a influência das TDIC na cultura escolar; em seguida, aponta-se para o papel da linguagem da internet e o processo de letramento digital do aluno. Arrematando a discussão, as considerações finais, alertam para o papel da escola e do professor na reconfiguração dos sentidos e das estruturas curriculares impostas pela atual demanda do letramento digital.

\section{PRÁTICAS DE LINGUAGEM E PROCESSOS DE ENSINO E APRENDIZAGEM NA SOCIEDADE DA INFORMAÇÃO E DA COMUNICAÇÃO}

Na atual sociedade da informação e da comunicação, Gallo (2003, p. 81) considera que a aprendizagem precisa ser entendida como:

[...] algo que escapa, que foge ao controle, resistir é sempre possível. Desterritorializar os princípios, as normas da educação maior, gerando possibilidades de aprendizado insuspeitadas naquele contexto. Ou, de dentro da máquina opor resistência, quebrar os mecanismos como ludistas pós-modernos, botando fogo na máquina de controle, criando novas possibilidades.

Nessa configuração de encruzilhadas, chama-se a atenção para os processos de ensino e aprendizagem e as práticas de linguagem no espaço escolar, as quais têm sido construídas a partir do reconhecimento da pluralidade de sujeitos, vozes e diálogos que tecem os sentidos e (des) centralizam as noções de poder em torno do conhecimento, o qual, para que ocorra em uma dimensão processual, pressupõe o caráter da mediação e da horizontalidade nos modos de ser e fazer educação. Essa visão integrada e mediadora das relações entre os sujeitos da ação educativa (professores e alunos) acentua o caráter social da linguagem, como mecanismo articulador de uma dinâmica funcional dos modos de dizer e estar no mundo. Há, com isso, a necessidade de reconhecer, valorizar e legitimar essas ações de linguagem, com vistas a construção do conhecimento prevista no currículo.

Toda essa dimensão educacional e linguageira deve ser situada na atmosfera dos fenômenos digitais, midiáticos e tecnológicos que dão o tom e as formas como os sujeitos se relacionam entre si, com os outros e com o mundo a sua volta. A transitoriedade dos tempos, que circunscreve a dinâmica do mundo real e impõe a lógica do virtual, traz à tona a necessidade de relativizar formas, tipos, dinâmicas e processos de cognição, relacionados às formas específicas de ensinar e aprender. Nesse percurso, "o conhecimento é a navegação em um oceano de incertezas, entre arquipélagos de certezas" (MORIN, 2002, p. 86), de areias movediças, paisagens mistas e correntezas de confluências de saberes. 
O sociólogo polonês Zygmunt Bauman, em uma entrevista ao Globo News (2016), na qual discorre sobre a "modernidade líquida" (2001), cita o biólogo Edward Osborne Wilson e diz que "estamos nos afogando em informações e famintos por sabedoria". Isso ocorre porque "não temos tempo de transformar e reciclar fragmentos de informações variadas numa visão em algo que podemos chamar de sabedoria. A sabedoria nos mostra como prosseguir [...] E é isso que estamos perdendo. Não sabemos como prosseguir".

Já John Naisbitt, futurólogo e autor de vários best-sellers sobre tendências globais, citado por Cipriani (2013) utiliza os termos: "informação" e "conhecimento" e diz que "estamos nos afogando em informação, mas famintos por conhecimento". Também, Burke (2016, p. 19) em seu estudo sobre o que é história do conhecimento, utiliza essas nomenclaturas:

"Estamos afogados em informações", por vezes escutamos, mas "famintos por conhecimento". Em sua peça A rocha (1934) T. S. Eliot já fazia essas perguntas, "Onde está a sabedoria que perdemos no conhecimento? e "Onde está o conhecimento que perdemos na informação?”. Tomando emprestada a famosa metáfora de Claude Lévi-Strauss, é válido pensar na informação como algo cru, e no conhecimento como algo cozido.

Concordo com os autores e noutro trabalho explicitei sobre a questão, também utilizando a nomenclatura desses dois últimos. Refiro-as como "noções que vale a pena visitar" (LIMA, 2019, p. 47):

a) Informação: todo o tipo de mensagem que chega até você, seja visual, sonora, escrita ou gestual. É a famosa poluição cultural, que advém de todos os tipos de mídias.

b) Conhecimento: é um apuramento de ideias, aquilo que é produtivo para a formação do repertório sociocultural do sujeito. Pode, inclusive, surgir a partir de um 'lixo cultural', de uma informação banal, que o sujeito interpreta e formula uma opinião crítica, fundamentada e situada em um nicho teórico-epistemológico.

Um fator que impulsionou esse movimento a nível mundial foi a expansão das mídias digitais e dos recursos tecnológicos, frutos do fenômeno da globalização, que aproxima culturas e expande possibilidades de interação entre os sujeitos. À medida que essas mudanças ocorrem, também a sociedade e, em especial, a escola, precisa se redefinir e se reorganizar, na tentativa de ampliar as redes de potencial cognitivo humano, no processo de produção, transmissão e difusão do conhecimento científico e cultural, de modo a viabilizar mudanças de concepções, conceitos e atitudes que superem as fragilidades de uma cultura tradicional.

Essa necessidade se impõe em face da mundialização da cultura tecnológica, que parece transpor os limites de um ensino tradicional, hierárquico e vertical, fazendo emergir uma noção de aprendizagem, como mediação e construção coletiva, priorizando um conceito de criação autônoma, que implica uma tomada de consciência e de direcionamento sobre o 


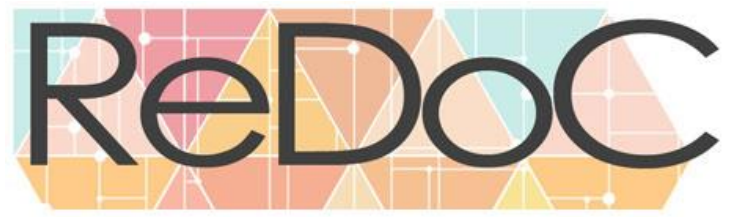

Revista Docência e Cibercultura

processo de ensino e aprendizagem em que os sujeitos estão envolvidos.

É enfocar, portanto, os usos e práticas de linguagens (múltiplas semioses), para produzir, compreender e responder a efeitos de sentido, em diferentes contextos e mídias. [...] Para participar de tais práticas com proficiência e consciência cidadã, é preciso também que o aluno desenvolva certas competências básicas para o trato com as línguas, as linguagens, as mídias e as múltiplas práticas letradas, de maneira crítica, ética, democrática e protagonista. (ROJO, 2009, p. 119) (Grifo da autora)

Portanto, a interatividade entre alunos e mídias digitais acarreta mudanças paradigmáticas nos processos educativos, que devem ser pensados desde a formação inicial do professor, preparando-o de forma eficiente, para a superação das fragilidades no ensino causadas pelo uso simples e ingênuo dos recursos tecnológicos. Essa mudança pressupõe, portanto, uma redefinição nas bases de sustentação filosófica e epistemológica que alicerçam suas práticas pedagógicas, nas quais estão inclusas as concepções de educação, ensino e aprendizagem, considerando o fenômeno da cibercultura, as influências das TDIC na cultura escolar, bem como, as questões políticas, sociais e culturais que envolvem os domínios do aprender e do ensinar mundo das tecnologias.

\section{O FENÔMENO DA CIBERCULTURA E AS INFLUÊNCIAS DAS TDIC NA CULTURA ESCOLAR}

Carvalho (2003, p. 20) compreende tecnologia, de maneira ampla, alertando que ela:

[...] perpassa todas as formações sociais, porque na produção das condições materiais de vida, necessárias a qualquer sociedade, é imprescindível a criação, apropriação e manipulação de técnicas que carregam em si elementos culturais, políticos, religiosos e econômicos, constituintes da concretude da existência social. Deste ponto de vista, tecnologia está intrinsecamente presente tanto numa enxada quanto num computador.

Parece lugar comum, dizer que hoje as tecnologias e mídias digitais alteraram os modos de interação humana, tendo em vista, as maneiras como o homem e a máquina dialogam e produzem sentidos, de forma individual e coletiva. No entanto, é mais que partir de um 'lugar comum' ou mesmo, modismo acadêmico, é reconhecer que nesse tempo de rápidas expansões e processamento de informações, a produção do conhecimento assumiu outros formatos, colaborando sobremaneira, para a ruptura com modelos estruturais, assentados no "paradigma conservador", que levam a mera reprodução e fragmentação do conhecimento científico e limitam o poder de criação dos sujeitos. No campo educacional, Behrens (2005, p. 19) referese à questão, tratando-a como fruto do paradigma newtoniano-cartesiano, que se sustenta a 
partir da segregação entre "ciência e ética, a razão do sentimento, a ciência da fé, enfim, mente e corpo".

Em contrapartida a essa visão, a autora propõe a adoção de abordagens pedagógicas, chamadas de "paradigmas inovadores": a progressista; a sistêmica (holística); e a do ensino com pesquisa (BEHRENS, 2005). Essas abordagens propiciam uma visão crítica, que vai de encontro aos anseios e as necessidades do homem contemporâneo, o qual se relaciona com o meio de forma interdependente, como protagonista de sua história. É essa a filosofia que sustenta os modos de interação e enunciação reflexiva e colaborativa propiciadas pelas mídias virtuais no processo de letramento digital dos interactantes do discurso, ou seja, ou sujeitos de aprendizagem mediada pelas TDIC, que vivem na sociedade da cibercultura, a qual é explicitada nas reflexões de Corrêa $(2004$, p. 2) e Lemos (2003, p. 1), respectivamente:

A cultura contemporânea passa a ser caracterizada pelo uso crescente de tecnologias digitais, cria-se uma nova relação entre a técnica e a vida social e, ao mesmo tempo, proporciona o surgimento de novas formas de agregação social de maneira espontânea no ambiente virtual, com práticas culturais específicas que constitui a chamada cibercultura.

A cibercultura nada mais é do que a cultura contemporânea em sua interface com as novas tecnologias de comunicação e informação, ela está ligada às diversas influencias que estas tecnologias exercem sobre as formas de sociabilidade contemporâneas, influenciando o trabalho, a educação, o lazer, o comércio, etc. Todas as áreas da cultura contemporânea estão sendo reconfiguradas com a emergência da cibercultura.

Essa configuração cria, portanto, uma vivência em sociedade de redes, "a nova morfologia social de nossas sociedades, e a difusão da lógica de redes modifica de forma substancial a operação e os resultados dos processos produtivos e de experiência, poder e cultura" (CASTELLS, 1999, p. 497). E, é inegável o quanto essas redes tem influenciado as formas de educação no Brasil, principalmente diante de um contexto marcado por dificuldades de acesso da população à escola, seja pelas questões de desigualdades econômicas ou sociais, culminando num processo de exclusão. Dudziak; Belluzzo (2008, p. 44) apontam que:

A emergência da Sociedade de Informação significou uma quebra de paradigmas em relação à trajetória tradicional de evolução sócio-econômica e educacional das sociedades modernas. Especialmente moldada a partir da rápida evolução das tecnologias de comunicação e informação, a sociedade da informação alicerça-se em um cenário essencialmente pós-moderno, informático, onde o indivíduo percebe certa angústia diante do impacto gerado pela velocidade com que a tecnologia tem evoluído e disponibilizado a informação, através dos meios de comunicação.

Embora a sociedade hoje, conviva - até relativamente bem - com uma série de recursos 
tecnológicos e midiáticos a sua disposição, a escola, que historicamente tem se apresentado como reflexo da sociedade, ainda apresenta dificuldades e resistências de apropriar-se dessas ferramentas a serviço de uma melhoria no processo de ensino e aprendizagem. Kenski (2012, p. 41) alerta para o fato de que:

Um saber ampliado e mutante caracteriza o estágio do conhecimento na atualidade. Essas alterações refletem-se sobre as tradicionais formas de pensar e fazer educação. Abrir-se para as novas educações, resultantes de mudanças estruturais nas formas de ensinar e aprender possibilitadas pela atualidade tecnológica, é o desafio a ser assumido por toda a sociedade.

A proposta emergente é a aproximação crítica, criativa e produtiva com esses meios, extraindo do mundo da internet e de suas faculdades interativas, maneiras dinâmicas e dialógicas de mediar o conhecimento, atendendo as demandas do currículo escolar e as configurações sociais da leitura e da escrita no mundo digital, que caracterizam o fenômeno do letramento digital, a serviço da inclusão, da democratização das formas de aprendizagem e da construção de atitudes ativas e responsivas frente ao contexto pós-moderno que impera.

\section{A LINGUAGEM DA INTERNET E O PROCESSO DE LETRAMENTO DIGITAL DO ALUNO}

Castells (2003, p. 287) alerta para o fato de que atualmente:

A Internet é o coração de um novo paradigma sociotécnico, que constitui na realidade a base material de nossas vidas e de nossas formas de relação, de trabalho e de comunicação. O que a Internet faz é processar a virtualidade e transformá-la em nossa realidade, constituindo a sociedade em rede, que é a sociedade em que vivemos.

Quanto ao desenvolvimento da leitura e da escrita na esfera da internet, Marcuschi (2010) destaca que a interferência das diversas mídias tecnológicas fez com que essas práticas assumissem novos formatos, outras dimensões na sociedade, instaurando-se assim, uma nova fase na história de seus desenvolvimentos. Esse fato ampliou os espaços de circulação dos textos, gêneros e suportes da escrita, no entanto, "a mudança mais notável aqui não diz respeito às formas textuais em si, mas sim à nossa relação com a escrita" (p. 18), uma vez que "escrever pelo computador no contexto da produção discursiva dos bate-papos síncronos (on-line) é uma nova forma de nos relacionarmos com a escrita, mas não propriamente uma nova forma de escrita" (p. 18), ou seja, foram os hábitos e os costumes do homem relacionarse com a escrita que se alteraram com o tempo, partindo da necessidade de responder aos comandos e às exigências de uma sociedade letrada. 


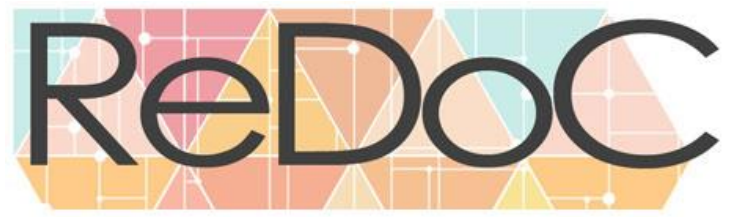

Revista Docência e Cibercultura

Daí, a pertinência de tratar sobre o letramento digital, entendendo-o como:

O conjunto de competências necessárias para que o indivíduo entenda e use a informação de maneira crítica e estratégica, em formatos múltiplos, vinda de variadas fontes e apresentada por meio do computador-internet, sendo capaz de atingir seus objetivos, muitas vezes compartilhados social e culturalmente. (FREITAS, 2010, p. 339)

O funcionamento dessas novas formas interacionais representa uma renovação nos modelos padrões de organização da escrita e uma questão desafiante para o leitor, exigindo a capacidade de compreender, nomear e articular diferentes propósitos, conforme os formatos ou modos como os textos se apresentam. Xavier (2002, p. 97) refere-os como modos de enunciação, "formas de expressão, comunicação e interação desenvolvidas e aperfeiçoadas pelos homens ao longo da história, para se relacionar comunicativamente com os outros e com o mundo"; e no espaço tecnológico, essa enunciação acontece de várias formas.

Essa total desterritorialização dos modos de envolvimento com a escrita, traz em uma consequência imediata, o surgimento de novos letramentos, ou seja, novas formas de leitura e interação crítica exigidas do leitor nas diferentes esferas sociais das quais participa. Isso implica uma noção hierárquica de organização da escrita, que no mundo da tecnologia, exige a necessidade de domínio de formas hibridas de expressão, como o sonoro, o visual, o gestual etc. Para Lemke (1998, p. 07), essas "novas tecnologias de informação, novas práticas de comunicação, e novas redes sociais tornam possíveis novos paradigmas para a educação e a aprendizagem", desafiando os velhos paradigmas, de modo que a exigência, pelo saber lidar, de forma crítica com as ferramentas desse mundo é um dos principais desafios enfrentados pela escola. É neste contexto de inevitáveis mudanças, que Lankshear; Knobel (2003, p. 155) apontam para os "novos letramentos", partindo do princípio de que:

[...] não foram apenas nossos letramentos que foram fortemente impactados pela revolução da tecnologia da informação. Mais profundamente, toda a base epistemológica em que está fundamentada a abordagem da escola ao conhecimento e à aprendizagem está sendo seriamente desafiada e [...] tornada obsoleta pela intensa digitalização da vida diária. (Grifo dos autores)

Reconhecendo as implicações disso no processo de ensino e aprendizagem, torna-se necessária uma mudança de concepção e atitudes pedagógicas adotadas pelas instituições de ensino. Soares (2002, p. 145) define o letramento "como estado ou condição de indivíduos ou de grupos sociais de sociedades letradas que desempenham, efetivamente, as práticas de leitura e de escrita, e participam de forma competente dos eventos de letramento", e, portanto, na esfera digital, é preciso considerar o fato de que:

A tela, como novo espaço de escrita, traz significativas mudanças nas formas de interação entre escritor e leitor, entre escritor e texto, entre leitor e texto e, até 
mesmo, mais amplamente, entre o ser humano e o conhecimento. [...] A hipótese é de que essas mudanças tenham consequências sociais, cognitivas e discursivas, e estejam, assim, configurando um letramento digital, isto é, um certo estado ou condição que adquirem os que se apropriam da nova tecnologia digital e exercem práticas de leitura e de escrita na tela, diferente do estado ou condição - do letramento - dos que exercem práticas de leitura e de escrita no papel. (SOARES, 2002, p. 151) (Grifo da autora)

Considera-se, diante disso, as múltiplas formas de letramento, chamado atualmente de letramentos sociais (Novos Estudos do Letramento (NLS) - New Literacy Studies, STREET, 1995; 2014), com as quais os sujeitos estão envoltos em seu cotidiano. Dentre esses, o letramento digital, que compreende os modos de inserção crítica no mundo das mídias eletrônicas e digitais, por meio de práticas de interação e colaboração que exigem competências discursivas e cognitivas para lidar com as tecnologias.

Para Xavier (2005), um indivíduo letrado digitalmente é aquele que assume posturas autônomas e críticas, sendo capaz de assumir mudanças nos modos de escrever e ler os diferentes códigos e sinais verbais e não verbais, como desenhos, imagens e sons, considerando que o suporte que comporta os textos digitais, também é digital. Barton; Hamilton (1998, p. 09) também destacam que:

Letramento não é o mesmo em todos os contextos; ao contrário, há diferentes Letramentos. A noção de diferentes letramentos tem vários sentidos: por exemplo, práticas que envolvem variadas mídias e sistemas simbólicos, tais como um filme ou computador, podem ser considerados diferentes letramentos, como letramento fílmico e letramento computacional (computer literacy).

A emergência do reconhecimento e familiarização com essa questão, por parte das instituições educativas constitui, portanto, o desafio necessário e a mola mestra para impulsionar a realização de práticas de ensino e aprendizagem ricas e dinâmicas, possibilitando ao aluno - fruto dessa cultura digital -, a assunção de novos posicionamentos críticos, expressos pela formalização de processos mentais superiores, pela ressignificação das formas verbais e discursivas do sujeito na leitura crítica e reflexiva do mundo.

Partindo disso, é necessário redefinir o currículo escolar, inserindo os recursos midiáticos, digitais e tecnológicos nos processos de ensino e aprendizagem, ajudando a escola a construir "novas formas de linguagem e interação humana" através da construção de "espaços de reflexão e mobilização de sentidos", possibilitando assim, "uma formação autônoma e consciente" (LIMA; SILVA, 2015, p. 1201), com a finalidade de promover o letramento digital e uma aprendizagem significativa dos sujeitos da aprendizagem. Almeida (2012, p. 10) recomenda: 
A busca de formas alternativas para a organização do trabalho pedagógico na escola que dê conta da aquisição dos diferentes letramentos [...] tem demando estudos e formação dos professores para colocar as tecnologias digitais a favor dos processos de ensino e de aprendizagem, promover a inclusão digital de alunos e professores e a reconstrução do currículo na prática social entre alunos e professores com a integração das tecnologias.

Nessa busca incessante pela criação de uma nova cultura do digital no contexto escolar, alguns estudos (ALMEIDA; SILVA, 2011; ALMEIDA; ALVES; LEMOS, 2014; ALMEIDA; VALENTE, 2014) realizados pelo Programa de Pós-Graduação em Educação: Currículo, da Pontifícia Universidade Católica de São Paulo (PUC/SP), apontam para a construção de um Web Currículo, uma tentativa de cooperação e integração, não apenas das disciplinas, mas entre os atores e as ressignificações possíveis de seus fazeres na cultura do tecnológico. Para Almeida (2016, p. 531):

A construção/reconstrução de web currículos acentua a relevância de reconfigurar o papel do professor e de ressignificar a organização educativa, que se torna um contexto de aprendizagem móvel, aberto e integrado com outros contextos, espaço ubíquo no qual o lugar físico está imbricado com o virtual, envolvido no fluxo contínuo de informações de diferentes domínios de conhecimento, com as quais professores e estudantes se deparam muitas vezes de forma imprevista. (Grifo da autora)

E, nesse contato, ainda que "imprevisto" exige a capacidade de potencialização do pensamento humano, imprimindo uma fronteira multidirecional entre os sujeitos e as formas como eles lidam com as práticas de linguagem. Desse modo, tem-se um processo ininterrupto e desafiador de pensar e repensar os saberes e fazeres que legitimam a prática docente na escola, sobretudo, por meio da mobilização da experiência humana.

Experienciado esse movimento de navegação com a linguagem da internet e os processos letramento digital que ela propicia ao aluno, transforma-se a técnica em espaço de intenções, interesses e lutas no desenvolvimento de competências, habilidades e condutas leitoras, de mundo e objetos específicos da materialidade digital pós-moderna.

\section{CONSIDERAÇÕES FINAIS}

A aproximação entre as possibilidades de interação facultadas pelo mundo da internet e o letramento digital dos alunos constituem uma das características fundamentais do contexto atual. A leitura, no sentido amplo dessa prática, pressupõe do sujeito, mais do que decodificação, mas apropriação crítica e transformadora dos produtos lidos. Esses produtos devem ser inseridos e transformados na dinâmica e no processo do contexto da cibercultura, 


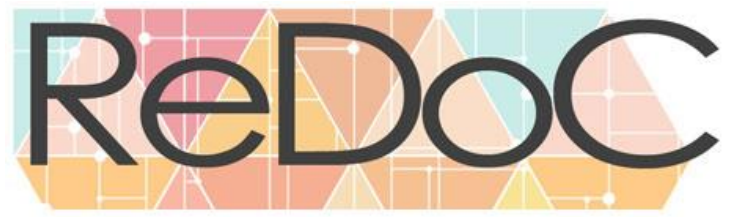

\section{Revista Docência e Cibercultura}

imprimindo novas cargas de valor e sentido à construção do saber cultural e escolarizado.

Com tantos recursos tecnológicos disponíveis atualmente, os educadores podem ser considerados parceiros, atuando como transformadores na qualidade social da escola, com responsabilidades e compromissos, tendo como competência, a capacidade de mobilizar os alunos em ultrapassar os obstáculos que venham a encarar em suas vidas, instigando-os a pensar e questionar, para garantir uma formação para o exercício da cidadania. Por isso, as mídias não devem ser excluídas do cotidiano dos alunos, pois elas disponibilizam muita informação e não devem ser deixadas de lado como se tem visto em muitos estabelecimentos de ensino.

Retomando Kenski (2001, p. 103), ela ensina que o papel do professor, nesse contexto é "ser o arauto permanente das inovações existentes. Ensinar é conhecer o desconhecido. A gente das inovações por excelência o professor aproxima o aprendiz das novidades, descobertas, informações e notícias orientadas para a efetivação da aprendizagem". Ou seja, é função sine qua non do docente contribuir para a abertura de espaços, projetos e mentes, levando-as por horizontes de transformação cultural do saber, por meio da interação tecnológica, digital e midiática, construindo assim, uma identidade ativa, criadora e letrada digitalmente no contexto da cibercultura.

\section{REFERÊNCIAS}

ALMEIDA, Maria Elizabeth Bianconcini de; SILVA, Maria da Graça Moreira da, Currículo, tecnologia e cultura digital: espaços e tempos de web currículo Revista e-curriculum, São Paulo, v. 7 n. 1 p. 01-19, abr., /2011. Disponível em: < https://revistas.pucsp.br/index.php/curriculum/article/viewFile/5676/4002 > Acesso: 16 dez. 2019.

ALMEIDA, Maria Elizabeth Bianconcini de; BORGES, Marilene Andrade F Borges; FRANÇA, George França. O uso das tecnologias móveis na escola: uma nova forma de organização do trabalho pedagógico. In: XVI ENDIPE - Encontro Nacional de Didática e Práticas de Ensino, Anais... UNICAMP - Campinas - 2012. Disponível em: < http://www.infoteca.inf.br/endipe/smarty/templates/arquivos_template/upload_arquivos/acerv o/docs/3900c.pdf >. Acesso em: 29 nov. 2019.

ALMEIDA, Maria Elizabeth Bianconcini de; VALENTE, José Armando. Currículo e Contextos de Aprendizagem: integração entre o formal e o não-formal por meio de tecnologias digitais. Revista e-curriculum. Revista e-Curriculum, São Paulo, v. 2, n. 12, p. 


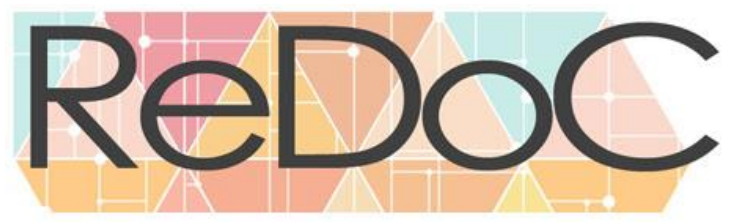

Revista Docência e Cibercultura

1162-1188, maio./out. 2014. Disponível em: <

https://www.redalyc.org/pdf/766/76632206005.pdf > Acesso em: 22 set. 2015.

ALMEIDA, Maria Elizabeth Bianconcini de; ALVES, Robson Medeiros; LEMOS, Silvana Donadio Vilela. Web Currículo: aprendizagem, pesquisa e conhecimento com o uso de tecnologias digitais. Rio de Janeiro: Letra Capital, 2014.

ALMEIDA, Maria Elizabeth Bianconcini de. Currículo e narrativas digitais em tempos de ubiquidade: criação e integração entre contextos de aprendizagem. Revista de Educação Pública, Cuiabá, v. 25, n. 59/2, p. 526-546, maio/ago. 2016. Disponível em: < http://periodicoscientificos.ufmt.br/ojs/index.php/educacaopublica/article/view/3833/2614 > Acesso: 16 dez. 2019.

BURKE, Peter. O que é história do conhecimento? São Paulo: Editora Unesp, 2016.

BARTON, David; HAMILTON, Mary. Local literacies: reading and writing in one community. London, Routledge, 1998.

BAUMAN, Zygmunt. Modernidade líquida. Rio de Janeiro: Jorge Zahar, 2001.

BAUMAN, Zygmunt. Identidade. Rio de Janeiro: Jorge Zahar, 2005.

BAUMAN, Zygmunt. Estamos num estado de interregno. Vivemos na modernidade líquida. Entrevista concedida jornalista Marcelo Lins, para o programa Milênio, do Globo News, em 01 jan. 2016: Acessível em: < http://www.conjur.com.br/2016-jan01/zygmuntbauman-neste-seculo-estamos-num-estado-interregno? > . Acesso em: 23 nov. 2019.

BEHRENS, Marilda Aparecida. O paradigma emergente e a prática pedagógica. Petrópolis: Vozes, 2005.

CARVALHO, Marília Gomes de. Relações de gênero e tecnologia: uma abordagem teórica. In: CARVALHO, Marília Gomes de (Org.). Relações de gênero e tecnologia. Curitiba: CEFET-PR, 2003. p. 15-28.

CASTELLS, Manuel. A sociedade em rede. São Paulo: Paz e Terra, 1999.

CASTELLS, Manuel. A sociedade em rede. In: MORAES, Denis (Org.). Por uma outra comunicação: mídia, mundialização cultural e poder. Rio de Janeiro: Record, 2003. p. 255287. 


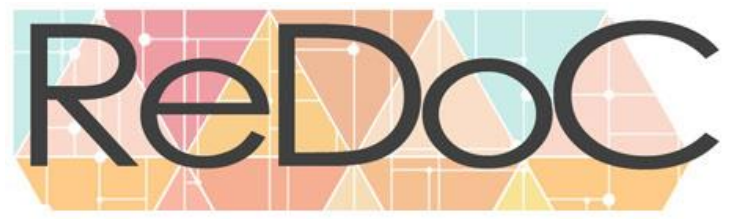

Revista Docência e Cibercultura

CIPRIANI, Fabio. Blog corporativo: aprenda como melhorar o relacionamento com seus clientes e fortalecer a imagem da sua empresa. São Paulo: Novatec Editora Ltda., 2013.

CORRÊA, Cynthia Harumy Watanabe. Comunidades virtuais gerando identidades na sociedade em rede. Ciberlegenda (UFF), Rio de Janeiro/RJ, Brasil, n.13, p. 1-14, 2004. Disponível em: < http://www.uff.br/ciberlegenda/ojs/index.php/revista/article/viewFile/226/122 >. Acesso em: 05 nov. 2019.

DUDZIAK, Elisabeth Adriana; BELLUZZO, Regina Célia Baptista. Educação, informação e tecnologia na sociedade contemporânea: diferenciais à inovação? Revista Brasileira de Biblioteconomia e Documentação: Nova Série, v. 4, n. 2, p. 44-51, jul./dez., 2008.

Disponível em: <

http://basessibi.c3sl.ufpr.br/brapci/_repositorio/2015/12/pdf_f9d59dfdcf_0000006192.pdf $>$. Acesso em: 04 nov. 2019.

EISENSTADT, Shmuel Noah. Modernidades múltiplas. Sociologia, problemas e práticas, $\mathrm{n}$. 35, p. 139-163, 2001.Disponível em: < http://biblioteca.versila.com/3334485 >. Acesso em: 03 dez. 2018.

FERRERAS, Norberto; BRUCE, Mariana. América Latina: modernidades alternativas. In: AZEVEDO, Cecília et al. (Orgs.). Outras modernidades: textos e propostas. Rio de Janeiro: FGV, 2009. p. 133-140.

FREITAS, Maria Tereza. Letramento digital e formação de professores. Educação em Revista, Belo Horizonte, v. 26, n.03, p. 335-352, dez. 2010. Disponível em: < http://www.scielo.br/pdf/edur/v26n3/v26n3a17 >. Acesso em: 29 nov. 2019.

GALLO, Sílvio. Deleuze e a educação. Belo Horizonte: Autêntica, 2003.

GARLAND, David. A cultura do controle: crime e ordem social na sociedade contemporânea. Trad. André Nascimento. Rio de Janeiro: Revan, 2008.

GIDDENS, Anthony. Modernidade e identidade. Rio de Janeiro: Jorge Zahar, 2002.

HALL, Stuart. A identidade cultural na pós-modernidade. 11. ed. Rio de Janeiro: DP\&A, 2011.

KENSKI, Vani Moreira. O papel do professor na sociedade digital. In: CASTRO, Amelia Domingues de; CARVALHO, Anna Maria Pessoa de (Org.). Ensinar a ensinar: didática para a escola Fundamental e Média. São Paulo: Ed. Pioneira Thompson Learning, 2001. p. 95-106. 


\section{ReDoC}

Revista Docência e Cibercultura

KENSKI, Vani Moreira. Tecnologias e ensino presencial e a distância. 9. ed. São Paulo: Papirus, 2012.

LANKSHEAR, Colin; KNOBEL, Michele. New literacies: changing knowledge and classroom learning. Buckingham: Open University Press, 2003.

LEMKE, Jay L. Metamedia literacy: transforming meanings and media. In: REINKING, D. et al (Eds.) Literacy for the 21st Century: technological transformation in a post-typographic world. Hillsdale, NJ: Erlbaum, 1998. p. 238-301. Disponível em: <

http://academic.brooklyn.cuny.edu/education/jlemke/reinking.htm $>$. Acesso em: 05 nov. 2019.

LEMOS, André. Palestra: Cibercultura. 2003. Disponível em: <

http://www.facom.ufba.br/ciberpesquisa >. Acesso em: 05 nov. 2019.

LEVY, Pierre. A inteligência coletiva: por uma antropologia do ciberespaço. Rio de Janeiro: Editora 34, 1994.

LIMA, Francisco Renato; SILVA, Jovina da. Tecnologias da Informação e da Comunicação na sala de aula: das resistências docentes a uma pedagogia do pensar a luz do letramento digital, tecnológico e midiático. In: IV Seminário Web Currículo e XII Encontro de Pesquisadores em Currículo da Pontifícia Universidade Católica de São Paulo: Contexto, Aprendizado e Conhecimento. Anais... São Paulo: PUC-SP, 2015. v. 1. p. 1200-1206. Disponível em: < http://www.pucsp.br/webcurriculo/downloads/anais/anais-ivwebcurriculo2015.pdf >. Acesso em: 04 nov. 2019.

LIMA, Francisco Renato. Fake news e campanhas de vacinação: a experiência com projetos de intervenção pedagógica na Educação Básica. São Carlos: Pedro \& João Editores, 2019.

MARCUSCHI, Luiz Antonio. Da fala para a escrita: atividades de retextualização. 10. ed. São Paulo: Cortez, 2010.

MORIN, Edgar. Os sete saberes necessários à educação do futuro. 6. ed. São Paulo: Cortez; Brasília, DF: UNESCO, 2002.

NEIRA, Marcos Garcia; LIPPI, Bruno Gonçalves. Tecendo a Colcha de Retalhos: a bricolagem como alternativa para a pesquisa educacional. Educ. Real., Porto Alegre, v. 37, n. 2, p. 607-625, maio/ago. 2012. Disponível em: <

http://www.scielo.br/pdf/edreal/v37n2/15.pdf > . Acesso em: 24 nov. 2019. 
ROJO, Roxane. Letramentos múltiplos, escola e inclusão social. São Paulo: Parábola, 2009.

ROJO, Roxane; BARBOSA, Jacqueline Peixoto. Hipermodernidade, multiletramentos e gêneros discursivos. São Paulo: Parábola, 2015.

SCHMIDT, Volker H. Múltiplas modernidades ou variedade da modernidade? Rev. Sociol. Polit., Curitiba, n. 28, p. 147-160, jun. 2007. Disponível em: < http://www.scielo.br/pdf/rsocp/n28/a10n28.pdf >. Acesso em: 03 dez. 2018.

SILVA, Jovina da; LIMA, Francisco Renato. Multilinguagens, tecnologias e letramentos em EAD: questões didáticas no Ensino Superior. São Carlos: Pedro \& João Editores, 2018.

SOARES, Magda. Novas práticas de leitura e escrita: letramento digital. Educação e Sociedade, Campinas, v. 23, n. 81, p. 143-160, dez. 2002. Disponível em: < http://www.scielo.br/pdf/es/v23n81/13935.pdf >. Acesso em: 05 nov. 2019.

STREET, Brian V. Social literacies: critical approaches to literacy in development, ethnography and education. Harow: Pearson, 1995.

STREET, Brian V. Letramentos sociais: abordagens críticas do letramento no desenvolvimento, na etnografia e na educação. Trad. Marcos Bagno. São Paulo: Parábola, 2014.

XAVIER, Antônio Carlos. O hipertexto na sociedade da informação: a constituição do modo de enunciação digital. 2002. 220 f. Tese (Doutorado em Linguística) - Instituto de Estudos da Linguagem. Universidade Estadual de Campinas, Campinas, 2002.

XAVIER, Antônio Carlos. Letramento digital e ensino. In: SANTOS, Carmi Ferraz; MENDONÇA, Márcia (Orgs.). Alfabetização e letramento: conceitos e relações. Belo Horizonte: Autêntica, 2005. p. 133-148.

YOUNG, Jock. The vertigo of late modernity. London: Sage Publications, 2007. 